\title{
Power Quality Analysis in Microgrid: An Experimental Approach
}

\author{
Arangarajan Vinayagam ${ }^{1 *}$, KSV Swarna1, Sui Yang Khoo', Alex Stojcevski² \\ ${ }^{1}$ Faculty of Science, Engineering and Built Environment, Deakin University, Geelong, Australia \\ ${ }^{2}$ Centre of Technology, RMIT University, Ho Chi Minh, Vietnam \\ Email: *avinayag@deakin.edu.au
}

Received 10 March 2016; accepted 22 April 2016; published 25 April 2016

Copyright (C) 2016 by authors and Scientific Research Publishing Inc.

This work is licensed under the Creative Commons Attribution International License (CC BY). http://creativecommons.org/licenses/by/4.0/

(c) (i) Open Access

\begin{abstract}
Microgrid (MG) integrated with Distributed Generation (DG) provides several benefits like reliable, secure, and high efficient of energy supply, while minimizing power loss, deferring expansion of power distribution infrastructures, and reduced carbon emission of energy supply etc. to the communities. Despite of the several benefits, there are several challenges existing due to the integration of different characteristics and technology of DG sources in MG network. Power Quality $(P Q)$ issue is one of the main technical challenges in MG power system. In order to provide improved $P Q$ of energy supply, it is necessary to analyse and quantify the $P Q$ level in MG network. This paper investigates the detail of $P Q$ impacts in a real MG network carried out through an experimental analysis. Voltage and frequency variations/deviations are analysed in both on-grid and off-grid mode of MG operation at varying generation and varying load conditions. Similarly unbalance voltage and current level in neutral are estimated at unbalanced PV generation and uneven load distribution in MG network. Also current and voltage THD are estimated at different PV power level. Finally the results obtained from the analysis are compared to that of Australian network standard level.
\end{abstract}

\section{Keywords}

Microgrid, Distributed Generation, Power Quality, Renewable Energy, Total Harmonic Distortion

\section{Introduction}

A small entity of electrical network known as MG plays an important role to provide secure, reliable, and sustainable energy supply to the critical loads of communities. MG accommodates several Distribute Generation (DG) sources like reciprocating engine generators, combined heat and power unit (CHP), micro turbine, Re-

\footnotetext{
${ }^{*}$ Corresponding author.
}

How to cite this paper: Vinayagam, A., Swarna, KSV, Khoo, S.Y. and Stojcevski, A. (2016) Power Quality Analysis in Microgrid: An Experimental Approach. Journal of Power and Energy Engineering, 4, 17-34. 
newable Energy (RE) sources (solar Photo Voltaic (PV), wind, mini hydro, bio energy, etc.), storage devices (batteries, flywheel, super capacitor, etc.) along with controllable and critical loads [1]. The MG should be capable to operate either in "grid connected" or "island mode" of operation. In "grid connected" mode, the power can be exported or imported between MG and utility grid according to the energy management of the system. In case of any major fault or power disturbance in the main grid, the MG switches over to stand-alone mode while still feeding power to the critical loads effectively [2] [3].

The DG in the MG provides several benefits such as improved energy efficiency by enabling the CHP units for co-generation and tri-generation application, reduction of power losses in the distribution network by incorporating DG sources nearby load center, which defers expansion of distribution network infrastructures, reduces carbon emission by enhancing the integration of distributed RE sources, etc. Despite of the benefits, DG in MG network creates several technical challenges like meshed power flow which affects the voltage regulation in distribution network, increases network fault level, bi-directional power flow and minimum fault current contribution from the power converter affects the coordinated operation of protective relay system. In addition to that, $\mathrm{PQ}$ issues like power variation, voltage and frequency deviation, voltage sag, voltage swell, voltage flicker, poor power factor, THD, unbalance voltage and unbalance current, etc. are also of great concern in MG distribution network [4]-[8]. In order to achieve improved quality of energy supply from the MG power system, it is necessary to quantify the level of PQ impacts in MG network at various scenarios.

Several research and analysis works are carried out by researchers in the topic of PQ in LV distribution network of MG power system. In [9] harmonic distortion level was analysed through Distribution System Simulator (DSS) software simulation in a PV integrated low voltage power network. Outcome of that study concludes that the voltage and current THD values are high in various conditions like higher level of PV penetration in MG network, at the far end feeder connecting point, at low load, and load operating at capacitive power factor. In [10] the static voltage stability limit level is analysed in a typical IEEE-30 bus standard network through continuation power flow method of simulation in MATLAB software environment. It is found that the voltage stability is in strong level at bus node 30, whereas it is in weak level at bus node 26. In [11] PQ issues are analysed through simulation using MATLAB software in a typical MG power network at different level of RE penetration and weather conditions. At $66.6 \%$ and $99.9 \%$ of RE penetration that the PQ issues are found high as compared to 33.3\% of RE penetration level. In [12] PQ issues are analysed in a typical solar PV integrated MG power system through simulation using PSS-SINCAL software. Power flow variation and voltage variation at local bus node is found during solar disturbance condition. As compared to PV integration with linear load and composite load connected bus nodes, THD is found high at bus node where non-linear load is connected. The unbalanced voltage level is around $1.48 \%$ in MG network due to the effect of uneven distribution of single phase load and PV generation. In [13] THD analysis is carried out at different level of PV penetration along with linear and non-linear load connected in the network. THD is found around $4 \%$ at higher level of PV penetration level along with linear load, whereas at minimum level of PV penetration with connection of non-linear load, THD level is found to be $5.06 \%$ which is above the standard limit. In addition, by applying three PQ indices, the power distortion, wave form distortion, and unbalance are evaluated in power system network. In [14] the voltage THD level is found high and exceeds the standard limit at above $50 \%$ of PV penetration in network. Also the reduction of voltage THD at bus node nearby substation where the penetration of PV is high as well as more loops in highly meshed network. In [15] through experimental assessment, it is found that the voltage THD remains within standard limit, however the current THD increased during less output power generation of PV (with respect to the full power rating) while at low solar irradiance or solar disturbance caused by the shadowing or cloud effect. Finally it is concluded that the current THD never exceeds $5 \%$ limit when PV power generation is above $60 \%$. Most of the research works on PQ analysis has been focused through software simulation in a typical MG or typical power system network. Only less number of research works has been done on PQ analysis in a real MG through the experimental approach. Thus in this paper, a detailed PQ analysis was carried out through the experimental work on real MG in Commonwealth Scientific and Industrial Research organization (CSIRO)Renewable Energy Integration Facility (REIF), Newcastle-Australia [16]. The PQ issues like; power variation, voltage and frequency variation, unbalance voltage and neutral current level, voltage and current THD were analysed at various scenarios.

Section 2 presents the configuration of MG network and details of MG associated elements, at CSIRO REIF, Newcastle-Australia. Section 3 describes the details of PQ issues and its effect on the MG network and also describes the standard limit for PQ level. Section 4 defines the method of analysis and addresses the results in de- 
tail. Section 5 concludes the paper and expresses further level of research work to be done in the future.

\section{MG Network Configuration}

MG in CSIRO facility has been configured with new grid management technologies and efficient energy mix from various types of Micro power sources and controllable load bank in a low voltage (LV) power system network. An efficient control of DG sources and high speed data acquisition can be done through Supervisory Control and Data Acquisition (SCADA) system facility available from the central control room. The Data Acquisition (DAQ) system has the facility to collect and logging the power system network data at higher sampling rate (50,000 samples/second) effectively. The MG network is interconnected with Utility grid through a single Point of Common Coupling (PCC) and the MG is capable of operating in both "on-grid" and "off-grid" mode of operation. A single line diagram of MG network configuration at CSIRO REIF is shown in Figure 1. The specification of each element integrated in MG network has been explained in detail.

\subsection{Solar PV}

Rooftop solar PV available in single phase and three phase type of configuration are employed during this experimental analysis. A 300 watts power rating of solar PV (LG 300 N1C-A3 MONOX NEON) with integration of micro inverter (ABB power-one Aurora Micro-0.3.I.OUTD) is grouped as single phase type and distributed in each phase as $7 \mathrm{~kW} / 7 \mathrm{~kW} / 11 \mathrm{~kW}$ respectively. Also in addition, two numbers of solar PV (Mono crystalline Silicon cell) with each power rating of around $12.5 \mathrm{~kW}$, integrated with $15 \mathrm{kVA}$ three phase inverter (SMA Sunny (15,000 TL) Tripower Economic Excellence) was considered. Overall installed capacity (including single phase and three phase PV) of solar PV approximately $50 \mathrm{~kW}$ was considered as the main RE source in MG network during this analysis.

\subsection{Micro Turbine (MT)}

Micro Turbine (Capstone C30) used in the real MG network is a gas operated, compact and ultra-low emission generator operating with maximum power rating of around $30 \mathrm{~kW}$. MT coupled synchronous generator supplies power to the MG through a back to back (AC-DC-AC) converter. MT acts as a master power source to fulfil the energy requirement in MG network during "Off-grid” mode of MG operation.

\subsection{Ultra-Battery Storage}

Operating voltage and Ampere hour capacity of each Ultra battery (Make: Furukawa) storage unit is around 24

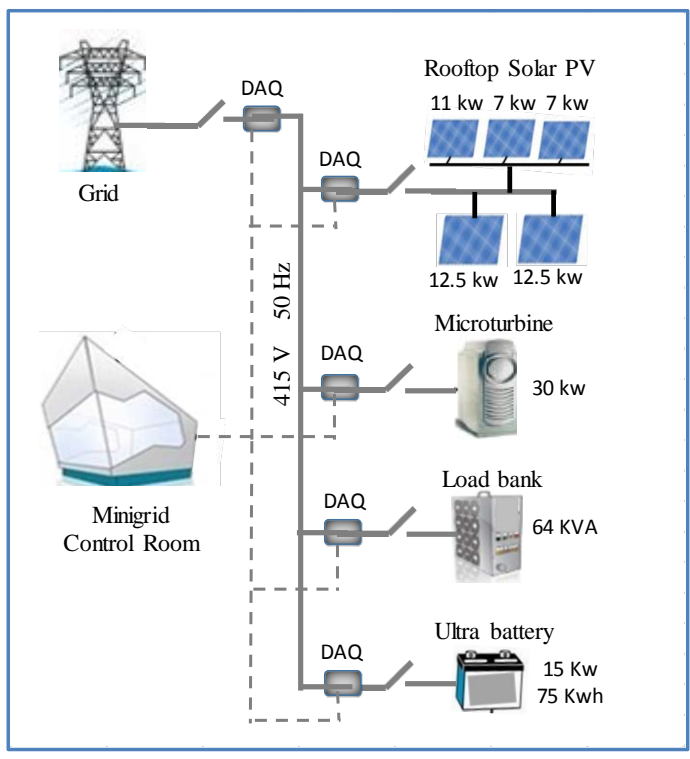

Figure 1. MG network configuration (CSIRO REIF). 
$\mathrm{V}$ and 1000 Ah respectively. There are three units of battery storage that are available in laboratory and each storage unit (5 kW/24 kWh) is integrated with $5 \mathrm{kVA}$ AC inverter (Selectronic PS1-single phase) in each phase. The operation of battery storage can be done through manual control.

\subsection{Load Bank}

A $64 \mathrm{kVA}$ rated capacity load bank is available with configuration of RLC (Resistor (R), Inductor (L), and Capacitor (C)) elements. The load bank can be operated as per the programmed typical load profile and also it can be operated through manual command.

\subsection{Data Acquisition (DAQ)}

Each source of elements in MG has its own DAQ, which collects the measured power parameters at higher speed rate. The DAQ for grid side (PCC point), solar PV, Micro Turbine, and Load bank are named as follows: DB DAQ, PV DAQ, MT DAQ, and Load DAQ respectively.

\section{Description of PQ Issues and Its Effects}

The term PQ in electrical network refers to maintaining wave form of voltage and current close to pure sinusoidal at rated magnitude and frequency [17]. Main PQ issues like; voltage and frequency variations, current and voltage harmonic distortions, unbalance voltage and current level in neutral line of MG network were analysed in this study.

\subsection{Frequency and Voltage Variation}

In order to get better voltage and frequency regulation in the MG network, it is necessary to maintain energy balance $($ Generation $=$ Consumption) every time [18]. However due to power variation from intermittent nature of RE sources and varying active and reactive power demand in distribution network, always there is a chance of voltage and frequency variation in power network. In "on-grid" mode of MG operation, grid acts as a buffer to maintain energy balance easily, whereas in "Off-grid" mode, maintaining voltage and frequency variation within tolerance level through energy balance is a major task in MG network. This is due to the lack of power inertia availability, challenges associated with the coordinated operation, and control of different types and characteristics of DG sources. Excessive variation of voltage and frequency can create a negative influence on the quality of energy supply and affects the performance of sensitive load connected in MG network.

\section{Allowable Range of Frequency and Voltage}

Nominal operating frequency of Power network is considered around $50 \mathrm{~Hz}$ in Australia. In National Electricity Market (NEM) regions, network frequency is maintained by Australian Energy Market Operator (AEMO). Allowable range of frequency level during normal operating condition is around $49.85 \mathrm{~Hz}$ to $50.15 \mathrm{~Hz}$ [19]. Table 1 shows the standard of frequency threshold level while there is no contingency event or load event in power network.

Nominal operating voltage in LV network is considered around $230 \mathrm{~V}$ for single phase supply and $400 \mathrm{~V}$ for three phase supply respectively. As per standard of AS 60038 [19] [20], allowable operating range of voltage level in LV network is around $216 \mathrm{~V}$ to $253 \mathrm{~V}(+10 \% /-6 \%$ of nominal voltage level $(230 \mathrm{~V}))$ for single phase, around $376 \mathrm{~V}$ to $440 \mathrm{~V}(+10 \% /-6 \%$ of nominal voltage level $(400 \mathrm{~V}))$ for three phase supply. Allowable range of voltage level in LV network as per AS 60038 standard [20] is shown in Table 2.

\subsection{Unbalance Voltage and Neutral Current}

Unbalance voltage and current is one of the main PQ issue in power system network. It refers to any deviation of phase voltage and current from its rated value with respect to the magnitude and phase angle. The unbalance current is a primary cause for unbalance voltage in network. Unbalance in LV network may occur due to the following reasons; uneven distribution of single phase loads, uneven power generation from single phase type power sources, unbalanced three phase loads, unequal impedance of three phase distribution network, etc. [17]. Unbalance can create a situation in the network to draw excessive reactive power, mal-operation of protective system, due to the influence of negative and zero sequence voltage or current affects the performance of power 
Table 1. Allowable range of operating frequency.

\begin{tabular}{ccc}
\hline \multirow{2}{*}{ Frequency Standard } & \multicolumn{2}{c}{ Conditions } \\
\cline { 2 - 3 } & $\begin{array}{c}\text { Containment } \\
(99 \% \text { of the time) }\end{array}$ & $\begin{array}{c}\text { Stabilisation/Recovery } \\
\text { (within 5 minutes) }\end{array}$ \\
\hline No contingency or no Load event & $49.85 \mathrm{~Hz}$ to $50.15 \mathrm{~Hz}$ & $49.85 \mathrm{~Hz}$ to $50.15 \mathrm{~Hz}$ \\
\hline
\end{tabular}

Table 2. Allowable range of operating voltage.

\begin{tabular}{ccc}
\hline \multirow{2}{*}{ Voltage Standard } & \multicolumn{2}{c}{ At Steady State Condition } \\
\cline { 2 - 3 } $230 \mathrm{~V}$ (phase to neutral) & Maximum & Minimum \\
\hline $400 \mathrm{~V}$ (phase to phase) & $253 \mathrm{~V}(+10 \%)$ & $216(-6 \%)$ \\
\hline
\end{tabular}

metering devices, reduce life span of electrical appliances, increases the power loss, etc. Voltage unbalance derating the induction motor with the effect of creating excessive heat and loss, creates thermal stress for Variable Speed Drive (VSD) electronic components with the effect of triple harmonic current, etc. Excessive neutral current level due to the effect of unbalance, leads to overloading of the distribution feeder and transformer with addition of creating heat losses. Also the neutral current caused common mode voltage affects the performance of sensitive electronic equipment's connected in the network [17] [18] [21]. There are two standard methods can be used to evaluate unbalance voltage and current in network. The International Electrotechnical Commission (IEC) which applies the symmetrical components for unbalance factor calculation and the National Electrical and Manufacturers Association (NEMA) method which applies magnitudes of system voltage or current.

\subsubsection{IEC Method of Calculation}

Unbalance voltage factor (VUF) is expressed in percentage, which is the ratio of negative sequence voltage to positive sequence voltage as shown in Equation (1). Similarly, unbalance current factor (IUF) is the ratio between negative sequence current to positive sequence current as shown in Equation (2) [17] [22]

$$
\begin{aligned}
& \text { VUF }=[V n / V p](\%) \\
& \mathrm{IUF}=[I n / I p](\%)
\end{aligned}
$$

where $V n$ is negative sequence voltage, $V p$ is positive sequence voltage, $I n$ is negative sequence current, and $I p$ is positive sequence current.

Also VUF can be calculated by using three phase line voltages as per the given below Equations (3) and (4) respectively [18] [21]

$$
\begin{gathered}
\beta=\frac{V_{a b}^{4}+V_{b c}^{4}+V_{c a}^{4}}{\left(V_{a b}^{2}+V_{b c}^{2}+V_{c a}^{2}\right)} \\
V U F=\sqrt{\frac{1-\sqrt{3-6 \beta}}{1+\sqrt{3-6 \beta}}}
\end{gathered}
$$

where $V_{a b}, V_{b c}, V_{c a}$ are the line voltages.

\subsubsection{NEMA Method of Calculation}

NEMA definition of VUF is the ratio of maximum deviation of voltage from average value to the average value of three voltages, as shown in Equation (5) [21].

$$
\mathrm{VUF}=\frac{V_{\text {mean }}-\operatorname{Max}\left(V_{a b}, V_{b c}, V_{c a}\right)}{V_{\text {mean }}}
$$

where $V_{a b}, V_{b}$, and $V_{c a}$ are the line voltages, and $V_{\text {mean }}$ is average values of $V_{a b}, V_{b c}, V_{c a}$. 


\subsubsection{Value of Neutral Current Calculation}

The neutral current $\left(I_{N}\right)$ can be calculated from the Equation (6) [23] as given below

$$
I_{N}=\sqrt{I_{A}^{2}+I_{B}^{2}+I_{C}^{2}-I_{A} I_{B}-I_{B} I_{C}-I_{C} I_{A}}
$$

where $I_{a}, I_{b}, I_{c}$ are the phase RMS current values.

\subsubsection{Allowable Unbalance Voltage Level}

As per Australian standard AS 4777 [20] [24], maximum allowable unbalance voltage level for LV network should be around 3\%. In LV network, the allowable unbalance voltage level over the average period of 1 minute, 10 minutes, and 30 minutes are shown in Table 3.

\subsection{Total Harmonic Distortion (THD)}

The non-sinusoidal wave form of voltage or current having frequencies other than fundamental frequency are called as Harmonics. In general, harmonic distortion can occur due to the non-linear current and voltage characteristics of equipment existing in the power system. The Power Electronics (PE) converter and non-linear loads are the main cause for current harmonics domination in the power network. Due to the system impedance, the injected current harmonics can cause the rise of voltage harmonics also in power network. Excessive harmonics in power network can cause the following issues; over loading of neutral in three phase power system, overheating of transformer and cables, voltage distortion in secondary side of distribution Transformer, increases the system power loss, affects the performance level of measuring instruments, mal operation of protective relays, increases di-electric losses and thermal stress in capacitor bank, increases copper loss and heat loss in electrical equipment's, etc. in power system network [18] [25].

\subsubsection{Current and Voltage THD Calculation}

The current and voltage THD can be calculated from the Equation 7 and Equation 8 [26] respectively. THD is the ratio of sum of r.m.s (root mean square) value of all the harmonic components up to a specific order to the r.m.s value of fundamental component

$$
\begin{gathered}
\mathrm{THD}_{\mathrm{I}}=\frac{\sqrt{I_{h 2}^{2}+I_{h 3}^{2}+I_{h n}^{2}}}{I_{h 1}^{2}}(\%) \\
\mathrm{THD}_{\mathrm{V}}=\frac{\sqrt{U_{h 2}^{2}+U_{h 3}^{2}+U_{h n}^{2}}}{U_{h 1}^{2}}(\%)
\end{gathered}
$$

where $I_{h 1}$ is the fundamental current harmonic, $U_{h 1}$ is the fundamental voltage harmonic, $I_{h n}$ is the current harmonic at highest order and $U_{h n}$ is the voltage harmonic at highest order.

\subsubsection{Current and Voltage THD Limit}

According to AS 4777 standard [27], maximum limit of current harmonics (up to $50^{\text {th }}$ order) injection from grid connected PV inverter should be less than 5\%. Current THD limit of odd and even harmonic components are shown in Table 4.

As per AS/NZS 61000.2.2 [20], compatibility level of voltage THD in LV network distribution network

\begin{tabular}{|c|c|c|c|c|}
\hline \multirow{2}{*}{ Unbalance voltage } & \multicolumn{4}{|c|}{ Negative sequence voltage ( $\%$ of nominal voltage) } \\
\hline & No contingency event & Credible contingency event & General & Once per hour \\
\hline Average period & 30 minutes & 30 minutes & 10 minutes & 1 minute \\
\hline Low voltage network (<10 kV) & $2 \%$ & $2 \%$ & $2.5 \%$ & $3 \%$ \\
\hline
\end{tabular}
should be less than $8 \%$.

Table 3. Compatibility of unbalance voltage level in LV network. 
Table 4. Current THD limit.

\begin{tabular}{cc}
\hline \multirow{2}{*}{ Odd and even harmonics } & THD limit \\
\cline { 2 - 2 } 3, 5 , 7 and 9 & Current THD (\%) \\
11,13 and 15 & $4 \%$ \\
7,19 and 21 & $2 \%$ \\
$23,25,27,29,31$ and 33 & $1.5 \%$ \\
$2,4,6$ and 8 & $0.6 \%$ \\
$10-32$ & $1 \%$ \\
\hline
\end{tabular}

\section{Method of Analysis}

Experiment analysis was carried in MG network (CSIRO, REIF) to quantify the impact level of following PQ issues; voltage and frequency variation, current and voltage THD, unbalance voltage, and neutral current level in MG network. Power sharing among DG sources, voltage and frequency variation level were analysed in both "on-grid" and "off-grid" mode of MG operation. In addition, THD, and unbalance voltage and neutral current level were analysed in "on-grid" mode of MG operation.

\subsection{Voltage and Frequency Variation}

Voltage and frequency variation level was estimated in "on-grid" mode of MG operation at different scenarios like; PV power variation with constant load, frequent power variation of power profile which is equivalent to typical solar disturbance was considered and implemented for MT generator operation. Similarly, voltage and frequency variation level was estimated in "off-grid" mode while actual power variation due to real solar disturbance and constant load condition. Finally the variation level in voltage and frequency was compared in both mode ("on-grid" and "off-grid") of MG operation.

\subsection{Unbalance Voltage and Neutral Current Level}

Unbalance voltage, and significant level of current in neutral was analysed with consideration of unbalanced PV generation and load condition. Uneven distribution of single phase PV generation and single phase load in LV network of MG was considered during this analysis. In addition, neutral current level was quantified and significant level of neutral current value was compared in both unbalanced PV generation and load condition. Finally the calculated unbalance voltage factor (UVF) was compared with AS 4777 standard limit.

\subsection{Current and Voltage THD}

Current and voltage THD level was quantified in each phase line at various power level of PV output $\left(P_{0}\right)$ with respect to their full power rating $\left(P_{r}\right)$ of overall PV installed capacity. Variation in actual solar irradiance which creates corresponding variation in PV power generation over the certain period of time was considered for this analysis. Odd and even harmonic current components was analysed and calculated THD results was compared with AS 4777 standard level.

\subsection{Analysis, Results and Discussion}

\subsubsection{Stepped Variation of PV Power with Constant Load: On-Grid Mode}

Nominal operating voltage in LV network of MG at CSIRO REIF is considered around $415 \mathrm{~V}$. Installed capacity of PV with $50 \mathrm{~kW}$ power rating was integrated along with $64 \mathrm{kVA}$ power rating of load bank in LV network of MG power system. Figure 2 shows the level of power variation from the PV source along with power consumption from the load bank. In order to get a typical PV power variation as shown in Figure 2, group of PV inverters were switched off in stepped level through manual command. The maximum power generation of PV was around $43.4 \mathrm{~kW}$, which varies and reaching the minimum level of around $5.9 \mathrm{~kW}$ through several steps. Total 


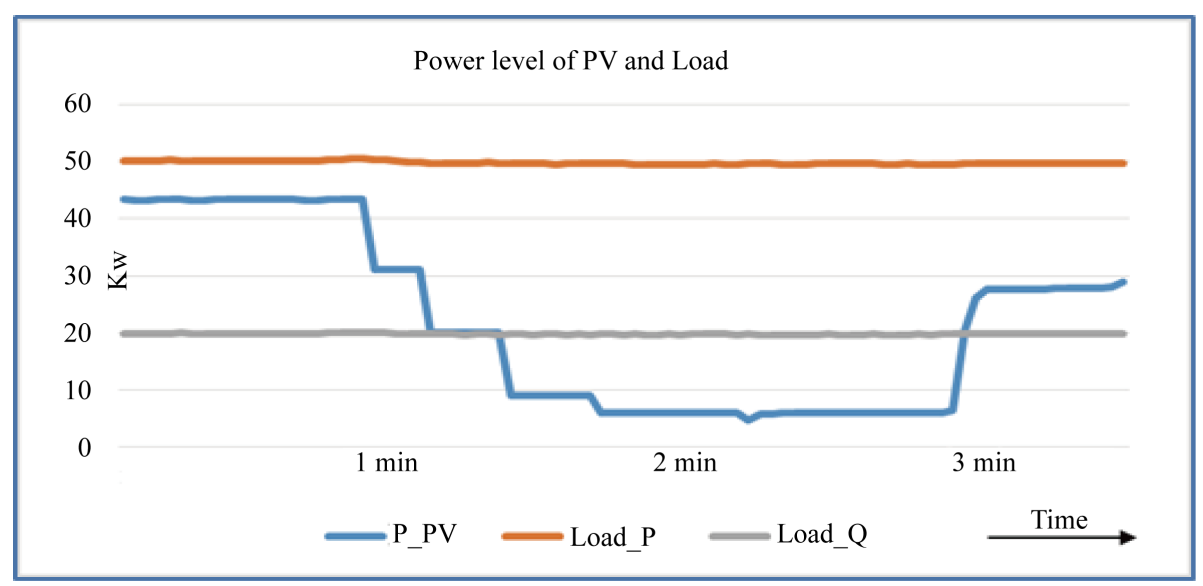

Figure 2. PV power versus Load power.

duration of analysis was considered with time frame of around 5 minutes. Throughout the duration of analysis, active and reactive power of the load bank was considered around $50 \mathrm{~kW}$ and $20 \mathrm{kVAR}$ respectively at constant level. Variation in frequency level at PCC as shown Figure 3, clearly indicates that the maximum level of frequency was around 50.12 Hzat maximum PV generation (43.4 Kw). Similarly, minimum level of frequency was around $49.98 \mathrm{~Hz}$ at minimum PV generation $(5.9 \mathrm{Kw})$. With reference to the nominal frequency $(50 \mathrm{~Hz})$ that the deviation in frequency level was around $+0.12 \mathrm{~Hz}$ while PV generation was at maximum level, whereas -0.02 $\mathrm{Hz}$ at minimum level of PV generation. Variation in voltage level at PCC as shown in Figure 4, indicates that the maximum level of voltage was around $409 \mathrm{~V}$ at maximum PV power generation. Similarly minimum level of voltage was around $403 \mathrm{~V}$ at minimum PV generation $(5.9 \mathrm{Kw})$. The voltage level at maximum PV generation was around $1.4 \%$ less and voltage level at minimum PV generation was around $2.9 \%$ less while compared with nominal voltage level (415 V) in MG network.

\subsubsection{Actual PV Power Variation with Constant Load: Off-Grid Mode}

This analysis was carried out over the 6 minutes period with integration of rooftop solar PV and MT generator along with load bank in MG network at off-grid condition. This analysis was carried out during real solar disturbance which creates frequent power variation in roof top solar PV. During solar disturbance (up to 2 minutes $40 \mathrm{sec}$ ), minimum and maximum level of power variation from connected solar PV was observed around 17.3 $\mathrm{kW}$ to $24.6 \mathrm{~kW}$ respectively, as shown in Figure 5. An integration of active power load (31 kW) was considered at constant level throughout this analysis. Figure 6 shows the output power level of MT generator which varies from minimum to maximum level of around $7 \mathrm{~kW}$ and $12.8 \mathrm{~kW}$ respectively. Power sharing among PV and MT generator along with power consumption from connected load is shown in Figure 7.

Variation of frequency level was observed from minimum to maximum of around $49.86 \mathrm{~Hz}$ to $50.14 \mathrm{~Hz}$ in MG network which is shown in Figure 8. Due to the effect of output power variation from solar PV, frequent variation in frequency level and requirement of frequent ramp up and ramp down of power from MT generator side was observed. As like frequency, number of voltage deviations was more during the solar disturbance condition. As shown in Figure 9, maximum and minimum variation in voltage level was observed around $432 \mathrm{~V}$ and $404 \mathrm{~V}$ respectively.

\subsubsection{Frequent Power Variation and Load Variation: On-Grid}

During this case study, Micro Turbine generator with $30 \mathrm{~kW}$ rated capacity and $64 \mathrm{kVA}$ load bank were integrated in MG network along with grid source. A 12 minutes duration of typical power (generation) and load profile has been considered for this analysis. A power profile of solar PV ( $25 \mathrm{~kW})$ followed by a typical solar profile has been considered. The power profile with frequent variation in power generation which is equivalent to a minute's level variation of solar irradiance in a typical solar profile has been considered. The typical solar profile as shown in Figure 10, clearly indicates that the maximum solar irradiance was around $924 \mathrm{Watts} / \mathrm{m}^{2}$ and minimum irradiance was $0 \mathrm{Watts} / \mathrm{m}^{2}$. Similarly, a typical load profile as shown in Figure 11 clearly indicates that the variation of load from maximum to minimum level was around $21.8 \mathrm{~kW}$ and $5.2 \mathrm{~kW}$ respectively. 


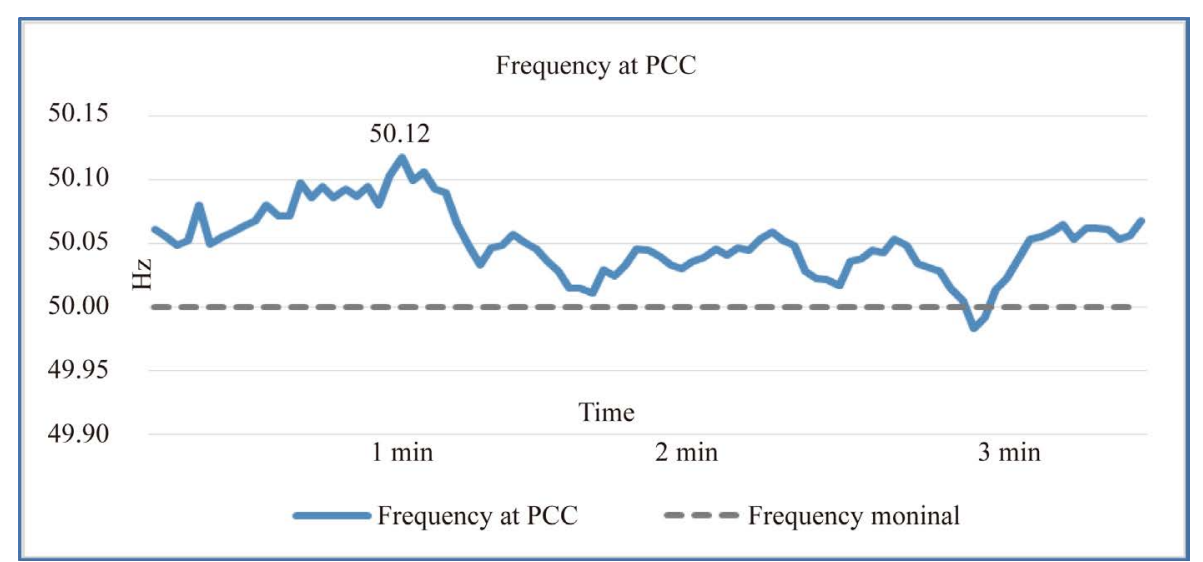

Figure 3. Frequency level (power variation with constant load, on-grid).

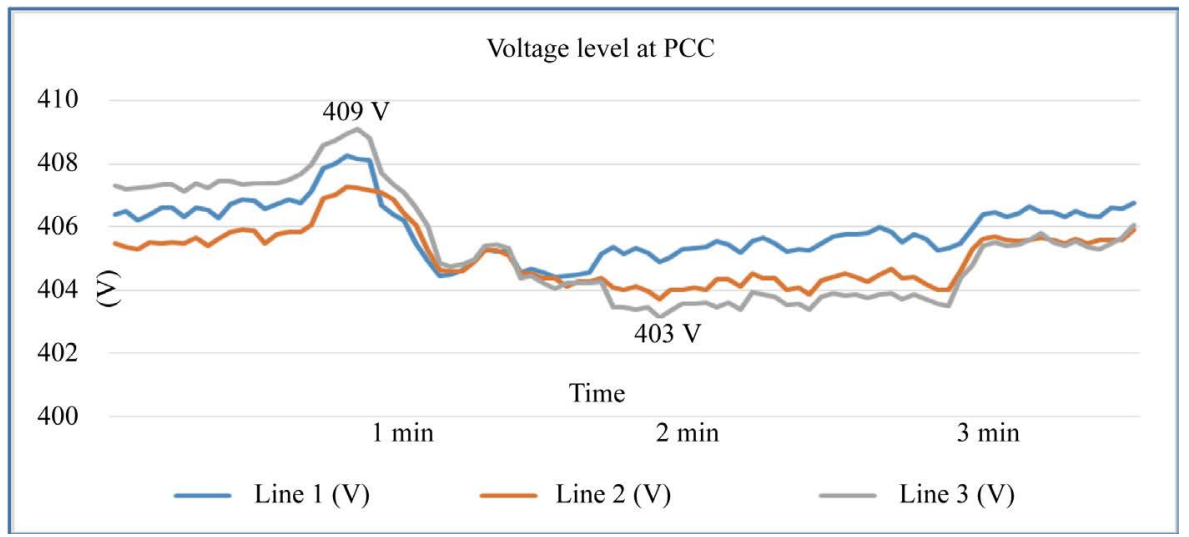

Figure 4. Voltage level (power variation with constant load, on-grid).

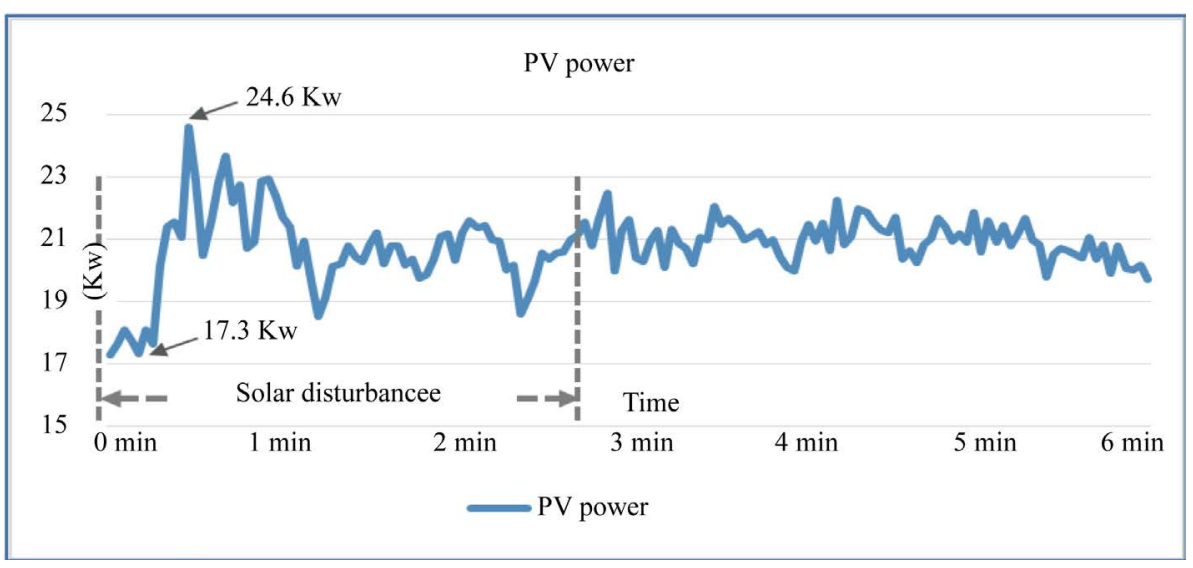

Figure 5. Power level of PV (constant load, off-grid).

Power set point as per varying power profile was given to load controller of MT generator. Similarly, active power set point command was given to load bank controller as per typical varying load profile. Active power output generation from MT generator and power consumption from load bank is shown in Figure 12.

As shown in Figure 13, maximum level of frequency at PCC was observed around $50.12 \mathrm{~Hz}$ where the load was at minimum of around $10 \mathrm{~kW}$ and maximum Turbine power of around $22 \mathrm{~kW}$. Similarly, minimum level of frequency was observed around $49.94 \mathrm{~Hz}$ while power generation was $0 \mathrm{~kW}$ and load was around $15 \mathrm{~kW}$. Maximum and minimum deviation of frequency was around $+0.12 \mathrm{~Hz}$ and $-0.06 \mathrm{~Hz}$ respectively while comparing to 


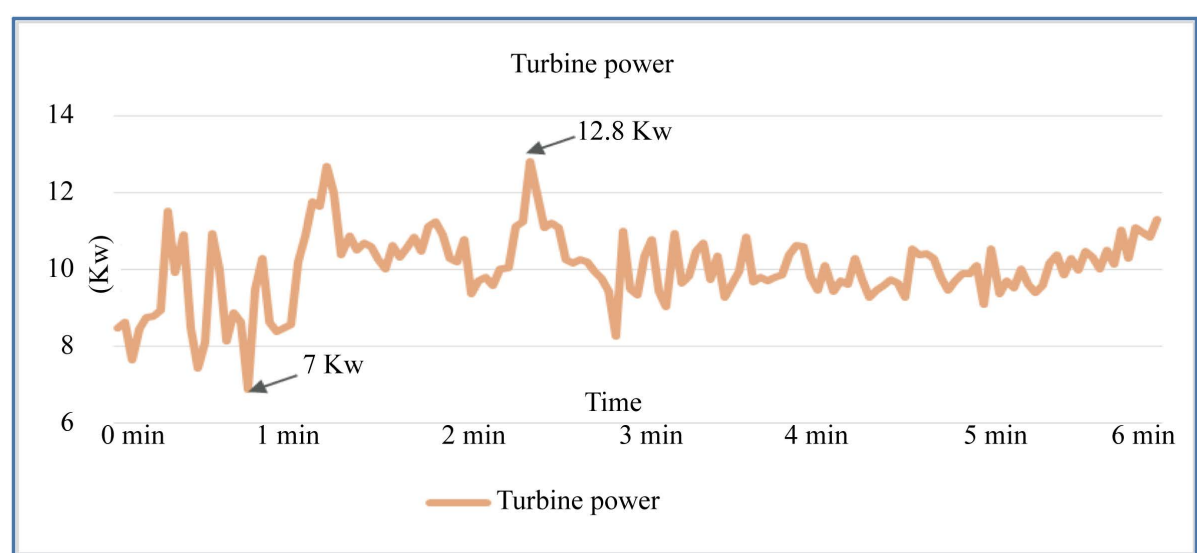

Figure 6. Power level of MT Generator (constant load, off-grid).

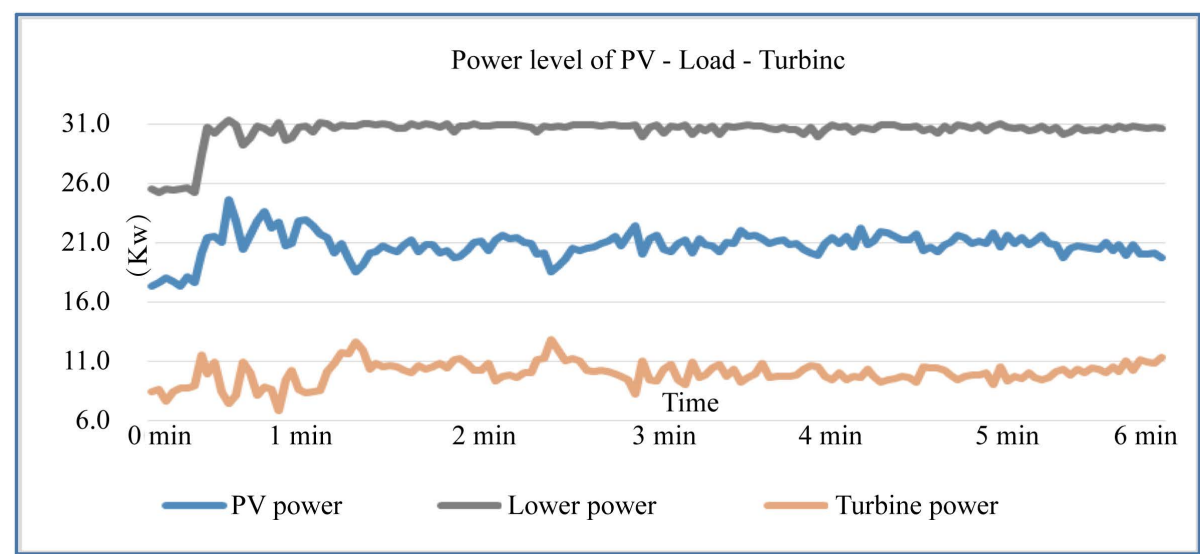

Figure 7. Power level of PV, MT, and load (constant load, off-grid).

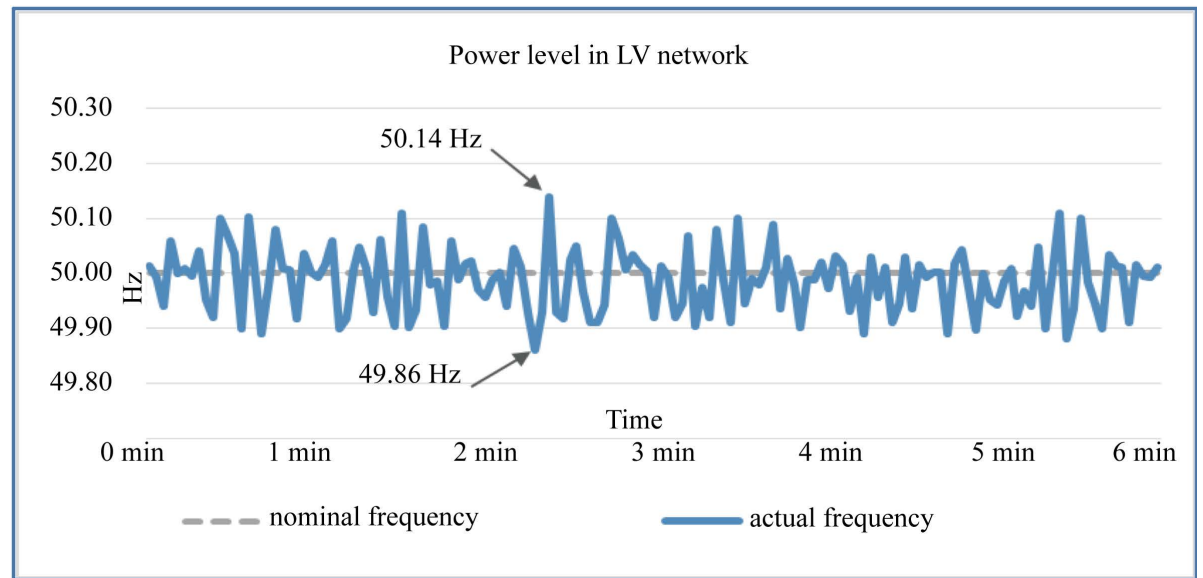

Figure 8. Frequency variation (constant load, Off-grid mode).

nominal level $(50 \mathrm{~Hz})$.

Voltage level at PCC varies according to varying power and load condition in MG network is shown in Figure 14. Maximum voltage level was observed around $412 \mathrm{~V}$ (4 minutes $47 \mathrm{sec}$ ) while power generation was at maximum level $(23 \mathrm{~kW})$ and minimum load $(10.29 \mathrm{~kW})$ condition. Similarly, minimum voltage level was observed around $405 \mathrm{~V}$ (11 minutes $50 \mathrm{sec}$ ) while there is no power generation $(0 \mathrm{~kW})$ and maximum load (19.46 $\mathrm{kW}$ ) condition. As compared with nominal voltage (415 V) level, the voltage level at maximum power generation 


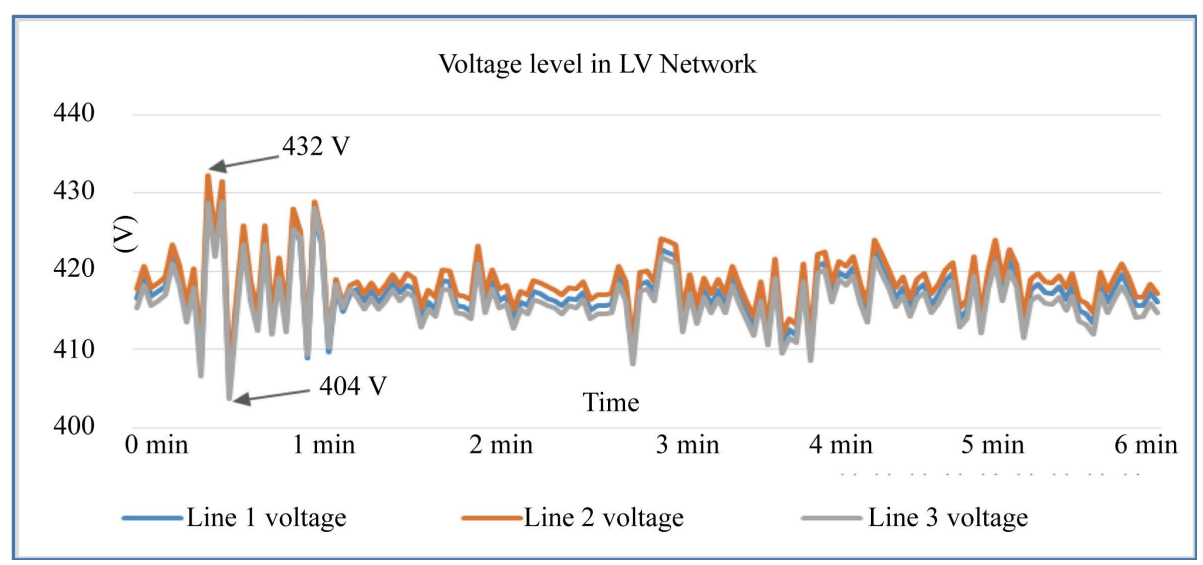

Figure 9. Voltage variation (constant load, off-grid mode).

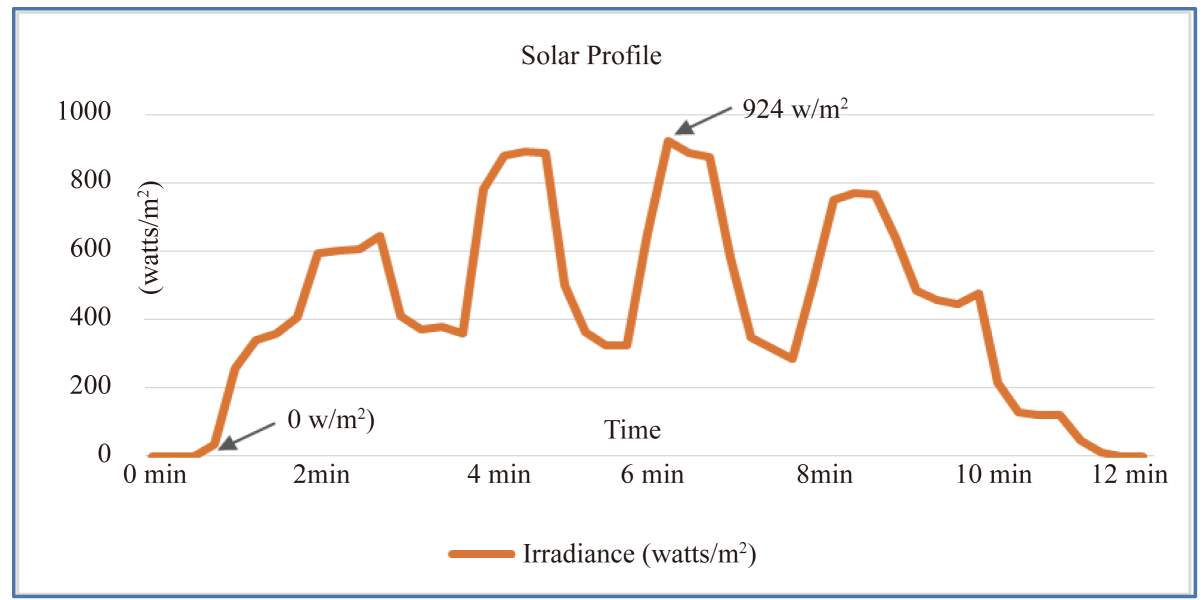

Figure 10. Typical solar profile.

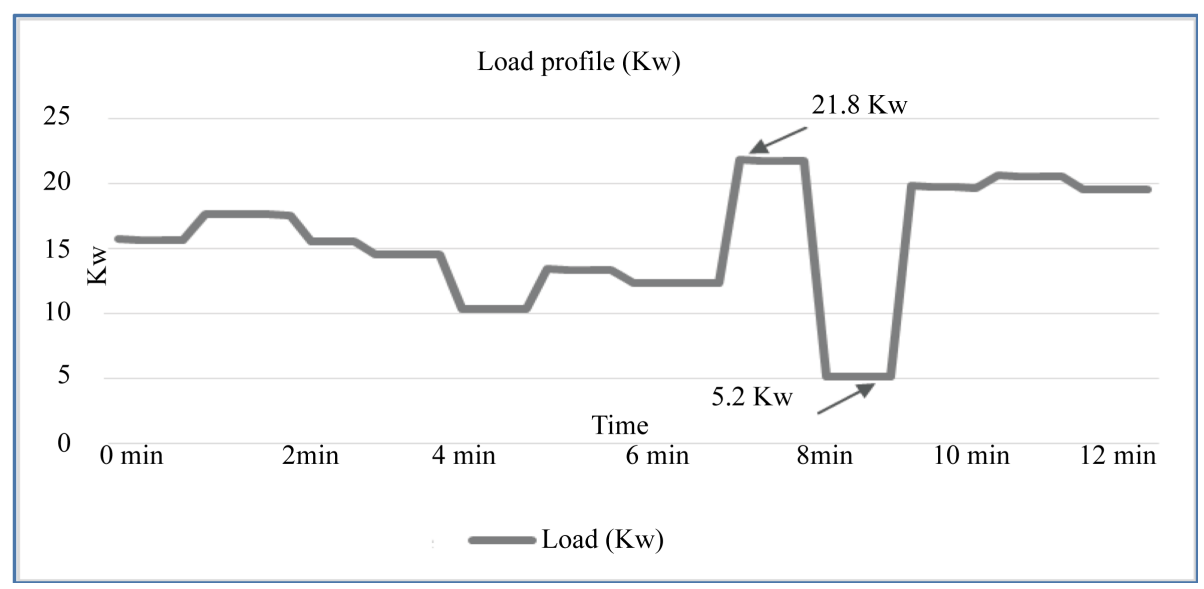

Figure 11. Typical load profile.

and minimum load condition was around $0.7 \%$ less and voltage level at no power generation and maximum load condition was around $2.4 \%$ less at PCC point of MG network.

Overall results of voltage and frequency variation/deviation level during “on-grid” and “off-grid” mode of MG operation is given in Table 5. Both frequency and voltage variation/deviation level with reference to nominal value were observed to be minimal and within the tolerance limit as per network standard level for on-grid 


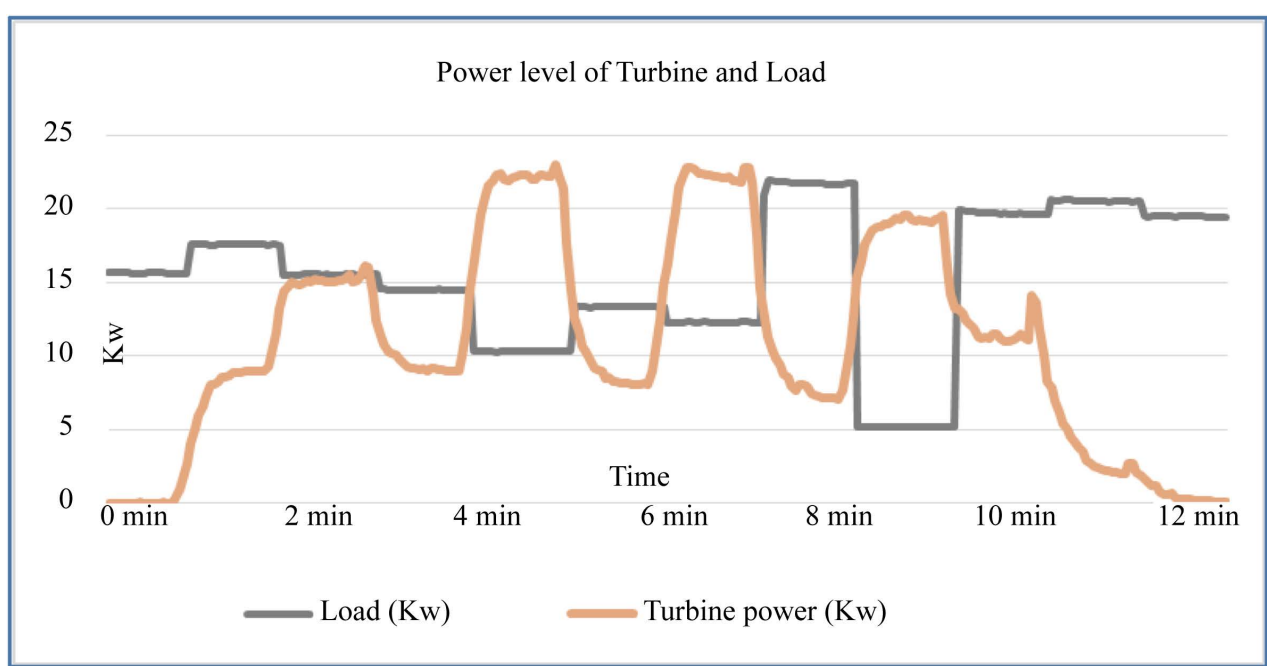

Figure 12. Active power of Turbine and load.

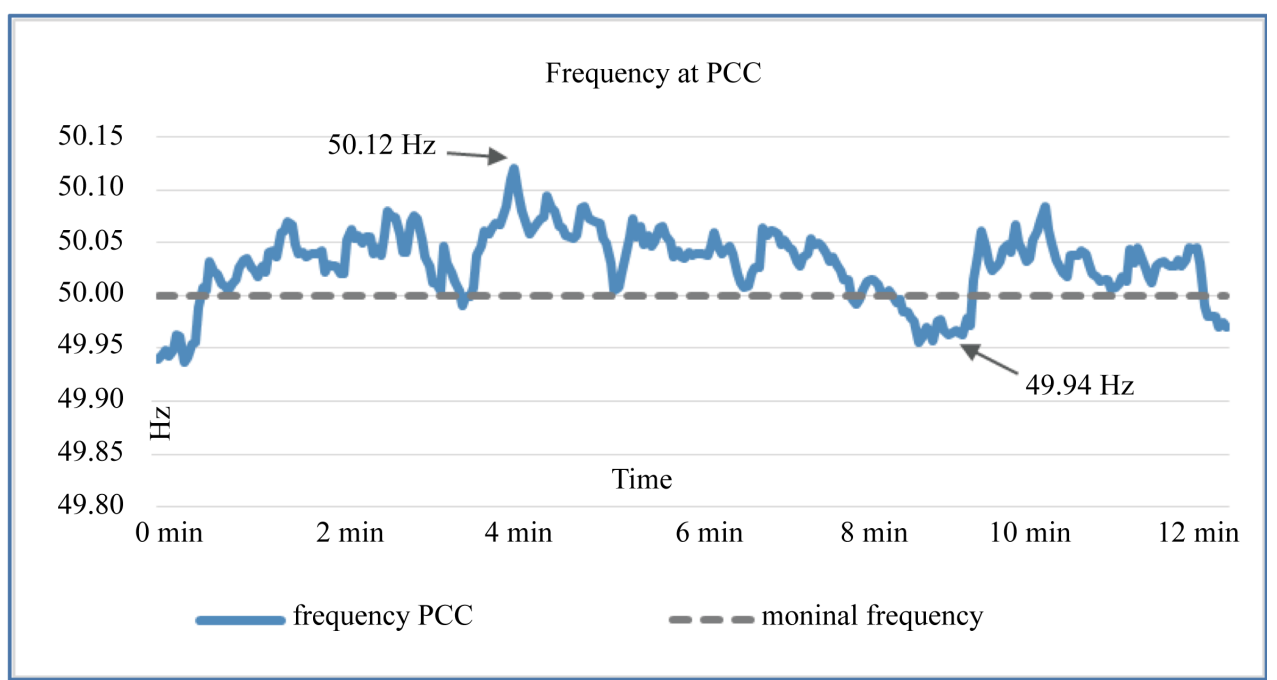

Figure 13. frequency level at PCC (varying load, on-grid).

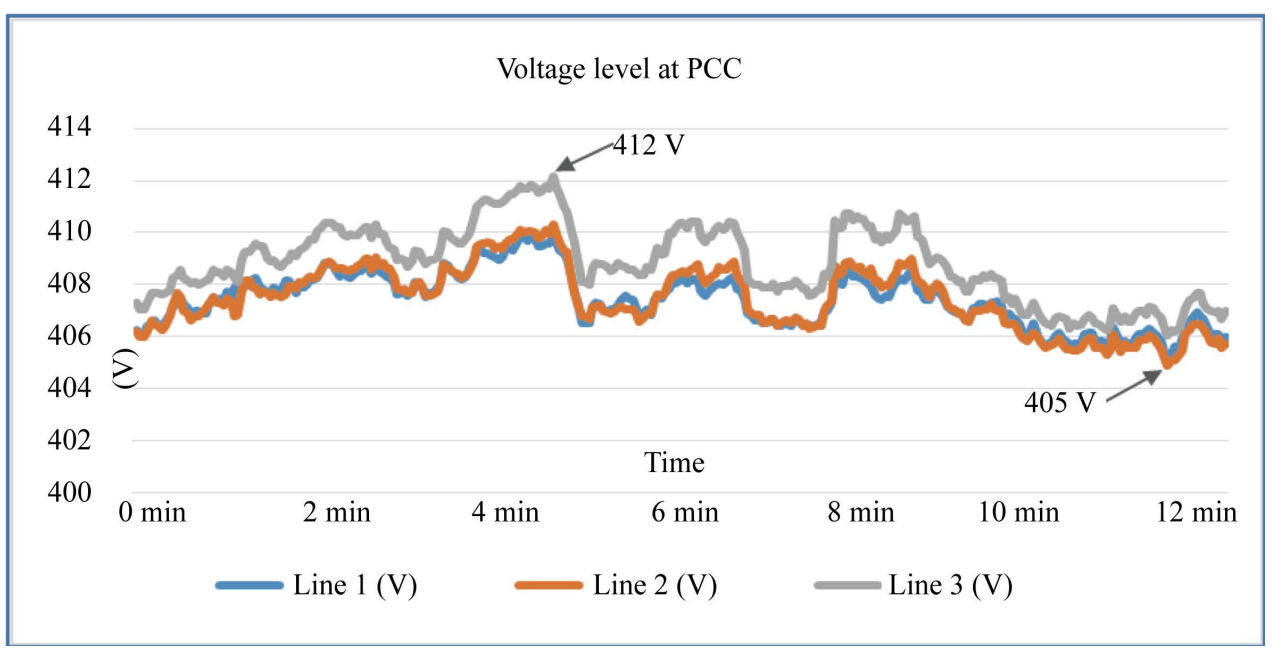

Figure 14. Voltage level at PCC (varying load, on-grid). 
Table 5. Overall result of frequency and voltage variation/deviation.

\begin{tabular}{ccccccccccc}
\hline \multirow{2}{*}{ Voltage and frequency analysis } & \multicolumn{3}{c}{ Frequency (Hz) } & \multicolumn{3}{c}{ Voltage (V) } \\
\cline { 2 - 10 } & \multicolumn{2}{c}{ variation $(\mathbf{H z})$} & deviation (Hz) & \multicolumn{2}{c}{ variation (V) } & deviation (\%) \\
\hline Pax & Min & Max & Min & Max & Min & Max & Min \\
\hline Power variation with constant load (On grid) & 50.12 & 49.98 & +0.12 & -0.02 & 409 & 403 & -1.4 & -2.9 \\
Power variation with constant load (Off grid) & 50.14 & 49.86 & +0.14 & -0.14 & 432 & 404 & +4.1 & -2.7 \\
Frequent power variation with varying load (On-grid) & 50.12 & 49.94 & +0.12 & -0.06 & 412 & 405 & -0.7 & -2.4 \\
\hline
\end{tabular}

mode of operation. This is because, the MG is connected with infinite power source called grid source which can maintain better voltage and frequency regulation in MG network easily.

As compared to the results from the on-grid mode of analysis, variation and deviation in voltage and frequency level was more in the off-grid mode. This is due to the lack of power inertia sources available in the MG network during off-grid mode of operation. However maximum and minimum variation in voltage and frequency level was maintained close to the tolerance level as per network standard level.

\subsubsection{Unbalance Voltage and Neutral Current Analysis}

Unbalance voltage and neutral current analysis was carried out in common point of LV distribution network with the unbalanced generation from single phase rooftop solar PV and uneven distribution of single phase load conditions. Figure 15 and Figure 16 shows the unbalanced power flow among each phases caused by the unbalanced power generation from solar PV in each phases and uneven distribution of single phase load in each phases respectively. Unbalance voltage level was estimated as per Equation (5) of NEMA standard and level of neutral current was estimated as per Equation (6) at various conditions like; unbalanced PV generation at $0 \mathrm{Kw}$ load, unbalanced PV generation with uneven load ( $1^{\text {st }}$ step), and unbalanced PV generation with uneven load ( $2^{\text {nd }}$ step) in further level. Figure 17 shows the voltage level with indication of unbalance voltage level according to various conditions as mentioned above.

The overall results of estimated unbalance voltage factor and neutral current values from this analysis are given in Table 6.

From the above results, it is clear that the estimated unbalance voltage factor and value of neutral current was minimal for unbalanced PV with no load condition in comparison to the other two conditions. UVF and neutral current value was more for unbalanced PV and uneven load ( $1^{\text {st }}$ step) as compared to unbalanced PV with no load condition. This is due to the cumulative effect of unbalanced PV and uneven distribution of load in network. The UVF and neutral current value was found more for unbalanced PV with uneven load ( $2^{\text {nd }}$ step) as compared to other two conditions. This is due to the cumulative effect of unbalanced PV and further level ( ${ }^{\text {nd }}$ step) of uneven load distribution in the MG network.

\subsubsection{Total Harmonic Distortion (THD) Analysis}

The current and voltage THD level was estimated in each phase of the network according to PV power output $\left(P_{0}\right)$ with respect to the full power rating $\left(P_{r}\right)$ of PV connected over that particular phase. At different power level in actual varying power profile of solar PV over the period of 15.25 minutes was considered for this analysis. Total $50 \mathrm{Kw}$ power rating of solar PV was involved in MG network during this analysis. Details in distribution of PV power contribution in each line of network according to their PV power ratings are given in Table 7. THD was analysed at four points of different PV power level which are shown in Figure 18. Current and voltage THD level was estimated as per THD calculation method, mentioned in Equation (7) and Equation (8) respectively. For THD calculation, maximum up to $25^{\text {th }}$ order $(1250 \mathrm{~Hz})$ of current and voltage harmonics has been considered. THD level was estimated at different level of PV power output. In all power level, low order components of even harmonics were found as minimum and neglected, whereas the results of harmonic currents for odd order components were considered during the maximum (44 kW) and minimum (13 kW) PV power level. The output results from this analysis for current THD, voltage THD, and current harmonics level for odd order components with reference to their appropriate standard THD limit are shown in Figures 19-21 respectively. 


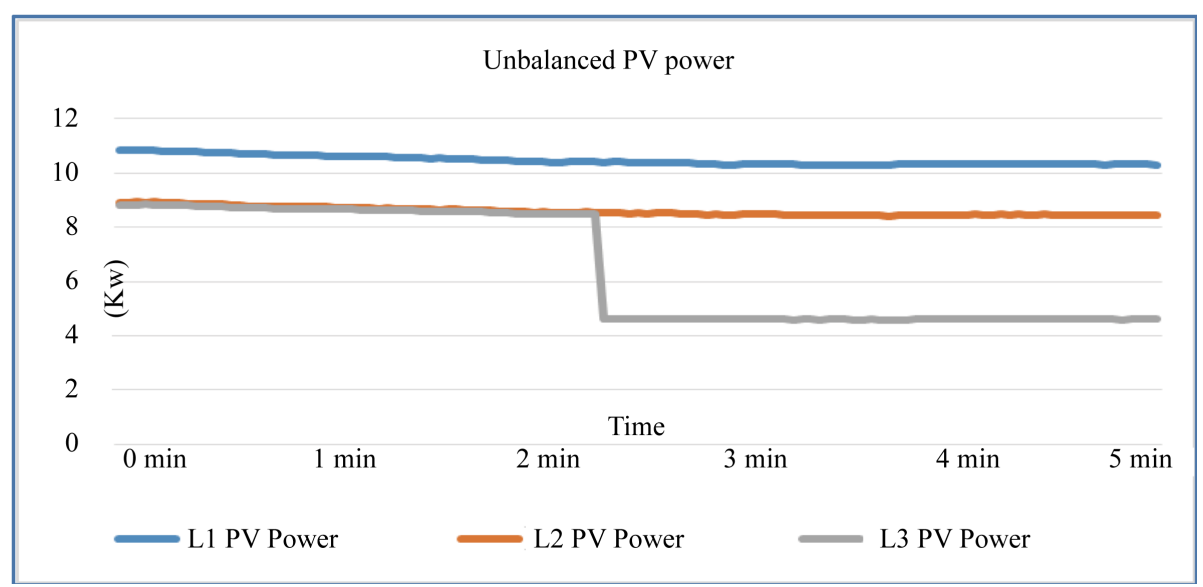

Figure 15. Unbalanced PV power generation.

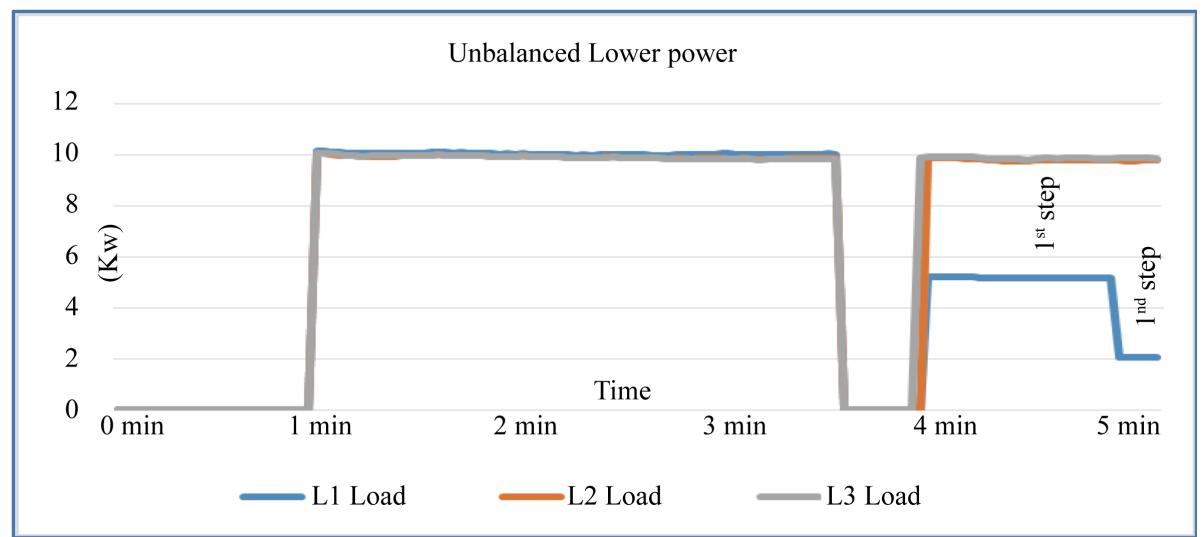

Figure 16. Power level of unbalanced load.

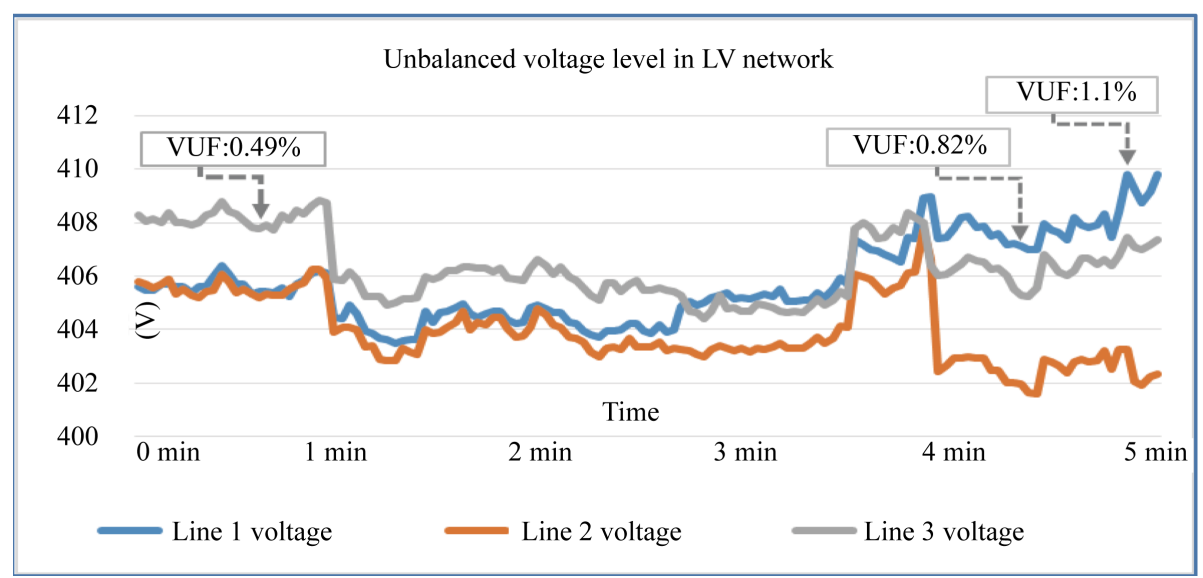

Figure 17. Voltage level at LV network.

The overall results of estimated current and voltage THD level at different PV power level is shown in Table 8. Similarly, results of harmonics current for the odd harmonic components, estimated at maximum and minimum PV power level is shown in Table 9.

In all cases, voltage THD level was found as minimum and within tolerance level of AS4777 standard. At 86\% of maximum PV power level $\left(P_{0} / P_{r}\right)$ in phase-A, and $89 \%$ in other two phases (phase-B and phase-C), the current THD was found as minimum of around $2.4 \%$ in phase-A, and $1.9 \%$ in phase-B and phase-C respectively. At 


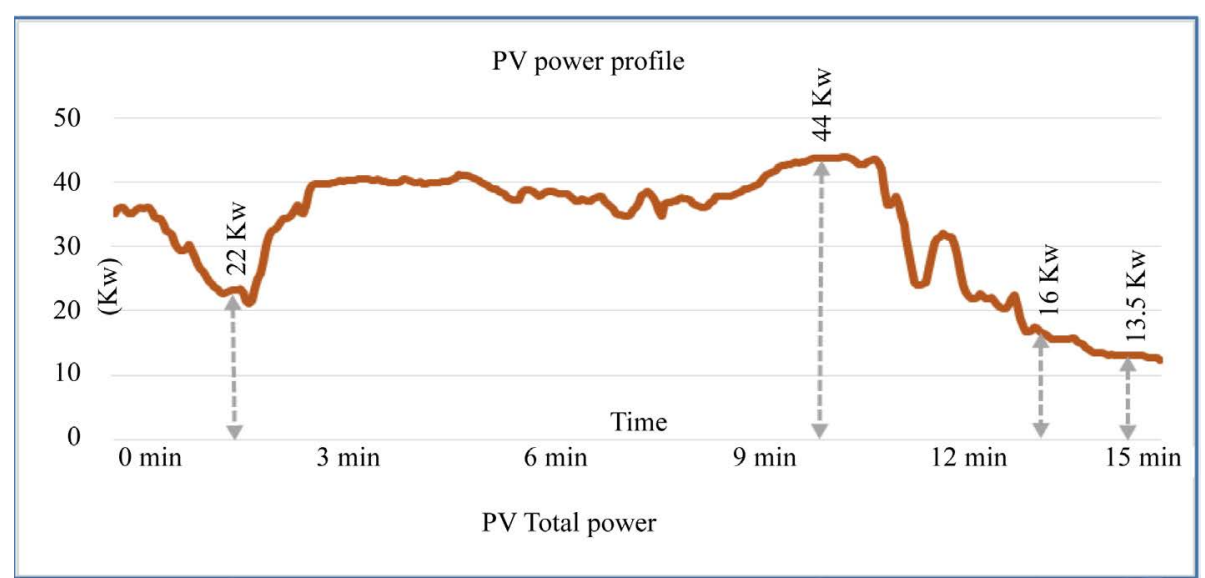

Figure 18. PV power profile.

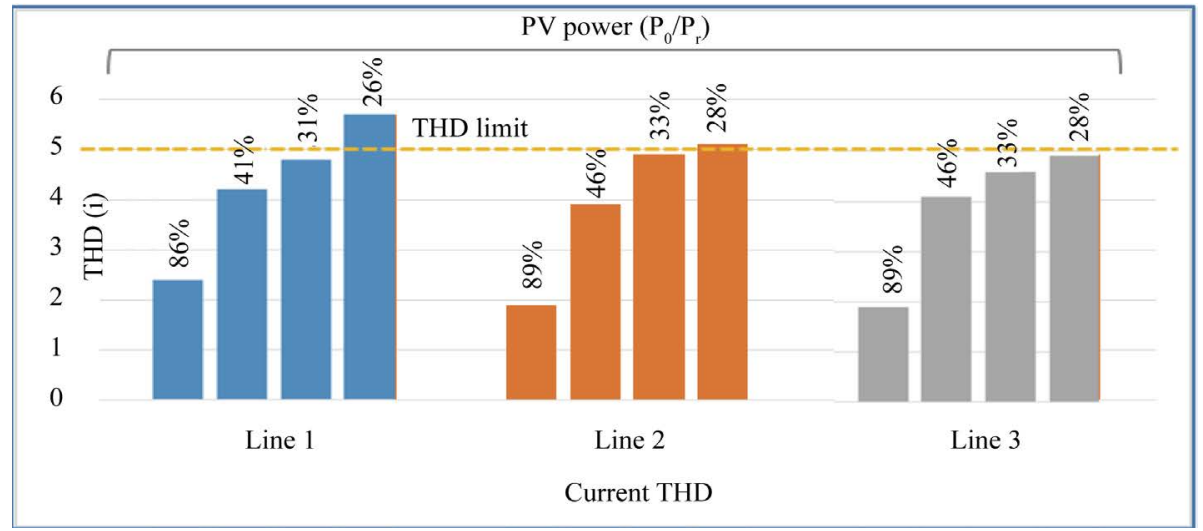

Figure 19. Current THD at different level of PV power.

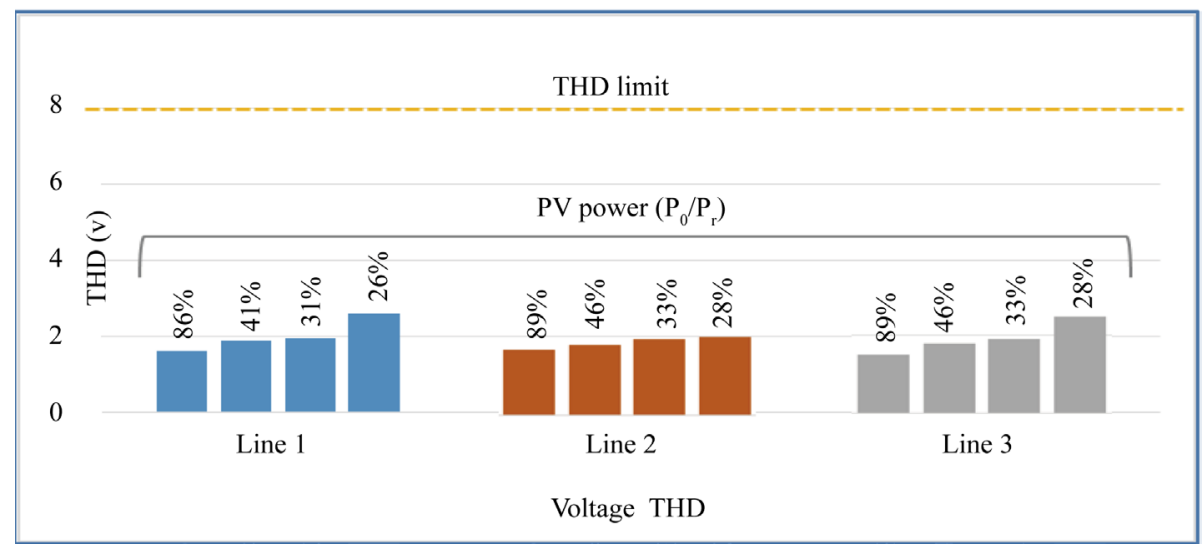

Figure 20. Voltage THD at different level of PV power.

$26 \%$ of minimum PV power level in phase-A, and 28\% in other two phases (phase-B and phase-C), the current THD level was found as high in phase-A (5.7\%), phase-B (5.2\%) which exceeds the THD limit and current THD in phase-C (4.9\%) was found as close to the THD tolerance level as per AS 4777 standard.

Results from Table 8 clearly indicate that the current harmonics in odd order component was high at minimum PV power level $\left(P_{0} / P_{r}\right)$ as compared to maximum power level. At minimum PV power level, current harmonics in $7^{\text {th }}$ order for phase-A $(3.9 \%)$ and phase-B $(3.8 \%)$ was found as high and close to the THD tolerance level and current harmonics in $13^{\text {th }}$ order for phase-A and phase-B (2.2\%) was found as above the THD 


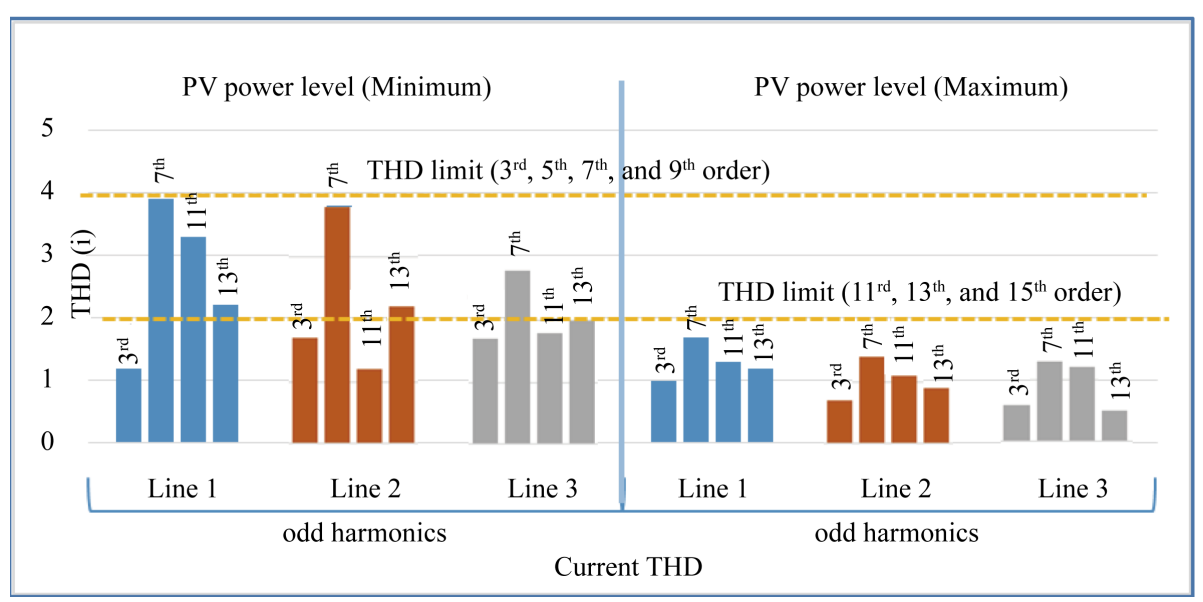

Figure 21. Current THD of odd harmonics.

Table 6. Overall results of UVF and neutral current.

\begin{tabular}{|c|c|c|c|c|c|c|c|c|}
\hline \multirow{2}{*}{ Unbalance voltage analysis } & \multicolumn{8}{|c|}{ PV generation (Kw) Load power (Kw) (\%) (amps) } \\
\hline & Ph-A & $\mathrm{Ph}-\mathrm{B}$ & $\mathrm{Ph}-\mathrm{C}$ & Ph-A & $\mathrm{Ph}-\mathrm{B}$ & In & $\mathrm{Ph}-\mathrm{C}$ & UVF \\
\hline Unbalanced PV generation with no load & 10.3 & 8.9 & 8.8 & 0 & 0 & 0 & 0.49 & 9.2 \\
\hline Unbalanced PV with uneven load ( $1^{\text {st }}$ step) & 10.3 & 8.5 & 4.6 & 5.2 & 9.8 & 9.9 & 0.82 & 20 \\
\hline Unbalanced PV with uneven load ( $2^{\text {nd }}$ step) & 10.3 & 8.4 & 4.6 & 2.1 & 9.8 & 9.9 & 1.1 & 33 \\
\hline
\end{tabular}

Ph-A. Phase A, Ph-B. Phase B, Ph-C. Phase C; UVF. Unbalance voltage factor; In. neutral current.

Table 7. PV power rating in each line.

\begin{tabular}{cccc}
\hline \multirow{2}{*}{ Type of solar PV } & \multicolumn{3}{c}{ PV configuration } \\
\cline { 2 - 4 } & Line 1 & Line 2 & Line 3 \\
\hline Three phase $(25 \mathrm{~kW}(2 * 12.5 \mathrm{~kW}))$ & 8.3 & 8.3 & 8.3 \\
Single phase & 11 & 7 & 7 \\
\hline
\end{tabular}

Table 8. Results of THD level at different PV power level.

\begin{tabular}{|c|c|c|c|c|c|c|c|c|c|c|c|}
\hline \multicolumn{4}{|c|}{ Line 1} & \multicolumn{4}{|c|}{ Line 2} & \multicolumn{4}{|c|}{ Line 3} \\
\hline $\begin{array}{c}\mathbf{P}_{0} \\
(\mathbf{K w})\end{array}$ & $\begin{array}{l}\mathbf{P}_{0} / \mathbf{P}_{\mathrm{r}} \\
(\%)\end{array}$ & $\begin{array}{c}\text { THD(i) } \\
\text { (\%) }\end{array}$ & $\begin{array}{c}\text { THD(v) } \\
\text { (\%) }\end{array}$ & $\begin{array}{c}\mathbf{P}_{0} \\
\text { (Kw) }\end{array}$ & $\begin{array}{l}\mathbf{P}_{0} / \mathbf{P}_{\mathbf{r}} \\
(\%)\end{array}$ & $\begin{array}{c}\text { THD(i) } \\
(\%)\end{array}$ & $\begin{array}{c}\text { THD(v) } \\
\text { (\%) }\end{array}$ & $\begin{array}{c}\mathbf{P}_{0} \\
(\mathrm{Kw})\end{array}$ & $\begin{array}{l}\mathbf{P}_{0} / \mathbf{P}_{\mathbf{r}} \\
(\%)\end{array}$ & $\begin{array}{c}\text { THD(i) } \\
\text { (\%) }\end{array}$ & $\begin{array}{c}\text { THD(v) } \\
(\%)\end{array}$ \\
\hline 16.6 & 86 & 2.4 & 1.6 & 13.7 & 89 & 1.9 & 1.6 & 13.7 & 89 & 1.9 & 1.5 \\
\hline 8 & 41 & 4.2 & 1.9 & 7 & 46 & 3.9 & 1.7 & 7 & 46 & 4.1 & 1.8 \\
\hline 6 & 31 & 4.8 & 1.95 & 5 & 33 & 4.9 & 1.85 & 5 & 33 & 4.6 & 1.9 \\
\hline 5 & 26 & 5.7 & 2.6 & 4.3 & 28 & 5.1 & 1.9 & 4.2 & 28 & 4.9 & 2.5 \\
\hline
\end{tabular}

Table 9. Results of harmonics current for odd components.

\begin{tabular}{ccccccc}
\hline \multirow{2}{*}{ Odd harmonics } & \multicolumn{3}{c}{ THD(i) \% at min PV power } & \multicolumn{3}{c}{ THD(i) \% at max PV power } \\
\cline { 2 - 7 } & Line 1 & Line 2 & Line 3 & Line 1 & Line 2 & Line 3 \\
\hline $3^{\text {rd }}$ order & 1.2 & 1.7 & 1.7 & 1 & 0.7 & 0.6 \\
$7^{\text {th }}$ order & 3.9 & 3.8 & 2.8 & 1.7 & 1.4 & 1.3 \\
$1^{\text {th }}$ order & 3.3 & 1.2 & 1.8 & 1.3 & 1.1 & 1.2 \\
$13^{\text {th }}$ order & 2.2 & 2.2 & 2 & 1.2 & 0.9 & 0.5 \\
\hline
\end{tabular}


limit as per AS4777 standard.

Finally based on the results from this analysis study, concluded that the current THD level was high at minimum PV power level $\left(P_{0} / P_{r}\right)$ and low at maximum PV power level $\left(P_{0} / P_{r}\right)$. This is due to the influence of fundamental current magnitude based on the generated PV power output over the harmonic currents of PV inverter.

\section{Conclusions}

In this study, PQ issues like frequency and voltage variation, unbalance voltage and neutral current level, and THD level were analysed and quantified in LV network of MG power system through an experimental approach.

The voltage and frequency level of variation/deviation were analysed in both "on-grid” and "off-grid” mode of MG operation at different scenarios. From the results, it was concluded that the variation and deviation in frequency and voltage level during on-grid mode of MG analysis were found as very minimum and within acceptable level of Australian network standard. As compared to on-grid mode, variation and deviation in voltage and frequency level were high during off-grid mode of MG analysis. However, in off-grid mode, the variation level was maintained within tolerance level of Australian network standard.

Unbalance voltage and neutral current level were found as minimum at unbalanced PV generation with no load condition. As compared to unbalanced PV generation with no load, and unbalanced PV generation with first level $\left(1^{\text {st }}\right.$ step) of uneven load, the unbalance voltage $(\mathrm{UVF}=1.1 \%)$ and neutral current $(\mathrm{In}=33 \mathrm{amps})$ level were found as high at unbalanced PV generation with second level ( $2^{\text {nd }}$ step) of uneven load condition. However in all cases, UVF was maintained within tolerance level as per AS4777 standard.

Results from the THD analysis study concluded that the voltage THD level was found as minimum and within tolerance level of AS4777 standard in all cases. The current THD level was high at minimum PV power level $\left(P_{0} / P_{r}\right)$ and low at maximum PV power level. Current THD level was found high and above the standard THD limit at 26\% of minimum PV power level in phase-A, and 28\% PV power level in phase-B. Similarly, at minimum PV power level $\left(P_{0} / P_{r}\right)$, current harmonics in $7^{\text {th }}$ order was found as high and close to the standard THD limit and current harmonics in $13^{\text {th }}$ order was found as high and above the standard THD limit.

The results from this analysis study can be used as a guideline to develop a real MG power system model with an improved PQ condition of energy supply for the sensitive loads connected in MG network effectively. Based on the outcome results, further research work will be focussed in developing and implementing optimum control strategies in a proposed typical solar PV integrated MG power model along with energy storage facility.

\section{Acknowledgements}

The authors would like to thankful and acknowledge the support of Mr. Tim Moore at CSIRO REIF-New castle, who provided access to use the facility and given guidance to conduct the experimental work at energy center.

\section{References}

[1] Hatziargyriou, C.S. and Liang, T. (2014) The Microgrids Concept, Microgrid: Architectures and Control. John WileyIEEE Press, Chichester, 1-24.

[2] Chowdhury, S., Chowdhury, S.P. and Crossley, P. (2009) Microgrids and Active Distribution Networks. The Institution of Engineering and Technology, London. http://dx.doi.org/10.1049/PBRN006E

[3] Li, R.S. and Zhou, F.Q. (2015) Microgrid Technology and Engineering Application. Elsevier, London, 14.

[4] Ackermann, T., Andersson, G. and Söder, L. (2001) Distributed Generation: A Definition. Electric Power Systems Research, 57, 195-204. http://dx.doi.org/10.1016/S0378-7796(01)00101-8

[5] El-Khattam, W. and Salama, M.M.A. (2004) Distributed Generation Technologies, Definitions and Benefits. Electric Power Systems Research, 71, 119-128. http://dx.doi.org/10.1016/j.epsr.2004.01.006

[6] Pepermans, G., Driesen, J., Haeseldonckx, D., Belmans, R. and D’haeseleer, W. (2005) Distributed Generation: Definition, Benefits and Issues. Energy Policy, 33, 787-798. http://dx.doi.org/10.1016/j.enpol.2003.10.004

[7] Bollen, M.H. and Hassan, F. (2011) Integration of Distributed Generation in the Power System. John Wiley \& Sons, Hoboken.

[8] Barker, P.P. and De Mello, R.W. (2000) Determining the Impact of Distributed Generation on Power Systems. I. Radial Distribution Systems. Power Engineering Society Summer Meeting, Seattle, 16-20 July 2000, 1645-1656. 
[9] Torquato, R., Trindade, F.C.F. and Freitas, W. (2014) Analysis of the Harmonic Distortion Impact of Photovoltaic Generation in Brazilian Residential Networks. 2014 IEEE 16th International Conference on Harmonics and Quality of Power (ICHQP), Bucharest, 25-28 May 2014, 239-243. http://dx.doi.org/10.1109/ICHQP.2014.6842776

[10] Ai, Q., Wang, X.H. and He, X. (2014) The Impact of Large-Scale Distributed Generation on Power Grid and Microgrids. Renewable Energy, 62, 417-423. http://dx.doi.org/10.1016/j.renene.2013.07.032

[11] Farhoodnea, M., Mohamed, A., Shareef, H. and Zayandehroodi, H. (2013) Power Quality Impact of Renewable Energy Based Generators and Electric Vehicles on Distribution Systems. Procedia Technology, 11, 11-17. http://dx.doi.org/10.1016/j.protcy.2013.12.156

[12] Vinayagam, A., Aziz, A., Swarna, K.S.V., Khoo, S. and Stojcevski, A. (2015) Power Quality Impacts in a Typical Microgrid. Atlantis Press, Amsterdam. http://dx.doi.org/10.2991/seee-15.2015.20

[13] Liu, Z., Xu, X., Abdelsalam, H.A. and Makram, E. (2015) Power System Harmonics Study for Unbalanced Microgrid System with PV Sources and Nonlinear Loads. Journal of Power and Energy Engineering, 3, 43-55. http://dx.doi.org/10.4236/jpee.2015.35004

[14] Begovic, M., Zhang, J., Novosel, D. and Cho, N. (2015) Harmonic Distortion in Microgrids and Distribution Systems with Photovoltaic Generators. 2015 48th Hawaii International Conference on System Sciences (HICSS), Kauai, 5-8 January 2015, 2586-2594. http://dx.doi.org/10.1109/HICSS.2015.311

[15] Barbu, V., Chicco, G., Corona, F., Golovanov, N. and Spertino, F. (2013) Impact of a Photovoltaic Plant Connected to the MV Network on Harmonic Distortion: An Experimental Assessment. Scientific Bulletin of Universitatea Politehnica din Bucuresti (UPB), Series C, 75, 179-193.

[16] CSIRO (2016) Renewable Energy Integration Facility. http://www.csiro.au/en/Research/EF/Areas/Electricity-grids-and-systems/REIF

[17] Chattopadhyay, S., Mitra, M. and Sengupta, S. (2011) Electric Power Quality. Springer, Dordrecht. http://dx.doi.org/10.1007/978-94-007-0635-4

[18] Baggini, A.B. (2008) Handbook of Power Quality. Wiley Online Library. http://dx.doi.org/10.1002/9780470754245

[19] Noone, B. (2013) PV Integration on Australian Distribution Networks. http://apvi.org.au/wp-content/uploads/2013/12/APVA-PV-and-DNSP-Literature-review-September-2013.pdf

[20] AUSGRID (2015) Network Standard. http://www.ausgrid.com.au/ /media/Files/Network/Documents/NS\%20and\%20NUS/NS113.pdf

[21] VIC GOSBELL (2002) Voltage Unbalance. http://www.elec.uow.edu.au/pqaustralia/main/images/stories/pqrctechnotes/technote6.pdf

[22] Gosbell, V.J., Herath, H.M.S.C., Perera, S. and Robinson, D.A. (2002) Sources of Error in Unbalance Measurements.

[23] Keljik, J. (2013) Electricity 3: Power Generation and Delivery. Nelson Education, Scarborough.

[24] Endevour Energy (2015) Network Power Quality Limits and Levels. http://asp.endeavourenergy.com.au/asp/standards/Documents/MDI0050.pdf

[25] Francisco De La Rosa (2006) Harmonics and Power Systems. CRC Press, Boca Raton.

[26] Das, J.C. (2015) Power System Harmonics and Passive Filter Designs. John Wiley \& Sons, Hoboken. http://dx.doi.org/10.1002/9781118887059

[27] Endeavour Energy (2014) Grid Connection of Embedded Generation through Inverters. http://asp.endeavourenergy.com.au/asp/standards/Documents/MDI0043\%20.pdf 